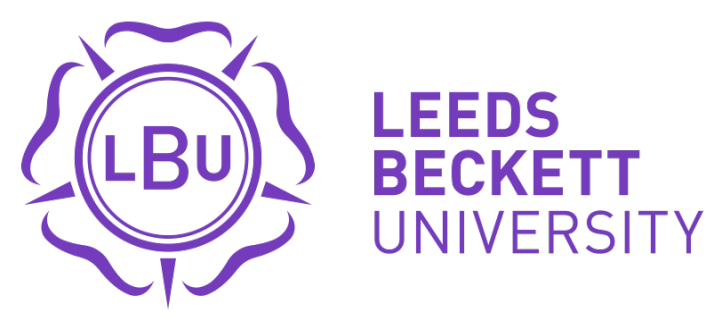

Citation:

Hardy, A and Glew, D and Gorse, C (2019) Assessing the equity and effectiveness of the GB energy price caps using smart meter data. Energy Policy, 127. pp. 179-185. ISSN 0301-4215 DOI: https://doi.org/10.1016/j.enpol.2018.11.050

Link to Leeds Beckett Repository record:

https://eprints.leedsbeckett.ac.uk/id/eprint/5574/

Document Version:

Article (Accepted Version)

Creative Commons: Attribution-Noncommercial-No Derivative Works 4.0

The aim of the Leeds Beckett Repository is to provide open access to our research, as required by funder policies and permitted by publishers and copyright law.

The Leeds Beckett repository holds a wide range of publications, each of which has been checked for copyright and the relevant embargo period has been applied by the Research Services team.

We operate on a standard take-down policy. If you are the author or publisher of an output and you would like it removed from the repository, please contact us and we will investigate on a case-by-case basis.

Each thesis in the repository has been cleared where necessary by the author for third party copyright. If you would like a thesis to be removed from the repository or believe there is an issue with copyright, please contact us on openaccess@leedsbeckett.ac.uk and we will investigate on a case-by-case basis. 


\title{
Assessing the Equity and Effectiveness of the GB Energy Price Caps using Smart meter Data
}

\author{
A. Hardy ${ }^{\mathrm{a}}$, D. Glew, C. Gorse \\ ${ }^{a}$ Leeds Beckett University, Leeds, LS2 9EN
}

\begin{abstract}
Keeping homes at a comfortable temperature and reducing household fuel bills are priorities for many governments. In the UK, several interventions have been implemented to achieve these objectives. This paper investigates one such policy lever - the Energy Price Cap - to understand if it has been designed and implemented efficiently and equitably. The price cap was introduced for customers on prepayment meters to combat increased levels of fuel poverty and a lack of competition in this group. However, the price cap was based on several assumptions of how energy is used. In this work, we assess how well the price cap accounts for real energy use using smart meter data. Households on economy 7 (EC7) tariffs were found to spend more than those on standard rate tariffs, as EC7 customers use more electricity during peak hours than assumed in government calculations. Additionally, many of the EC7 customers in this sample still use a considerable amount of gas, suggesting the EC7 heating product is either not sufficient, or is not being utilised in a cost-effective manner. Revisions to the input assumptions in government models for EC7 customers would therefore be beneficial in future price cap levels.
\end{abstract}

Keywords: Energy Price-Cap, economy 7, smart meters, Fuel Poverty

\section{Introduction}

\subsection{Domestic heating and health}

When a home is not kept sufficiently warm, occupants are at increased risk of several health problems. For example, cold homes have been linked to increased risk of anxiety and depression [1, 2], and the increased presence of mould can cause respiratory problems [3]. The simple solution to these health issues is to heat homes to a sufficient level. In the UK, Public Health England recommends a minimum temperature of $18^{\circ} \mathrm{C}$ to avoid the health issues associated with cold homes 4 ] and UK homes are, on average, heated to this temperature [5]. However, studies have also revealed significant variability in internal temperatures. A survey of 1,600 low-income households in the UK measured daytime winter indoor temperatures to be between $13.0^{\circ} \mathrm{C}$ and $21.8^{\circ} \mathrm{C}$ within the 5 th to 95 th percentile range [6]. A substantial number of homes in the UK are therefore not kept sufficiently warm, and the effects of these cold homes can be seen in national statistics. The UK Office of National Statistics suggests that there is a regular $20 \%$ spike in the mortality rate in winter, a quarter of which can be directly linked to homes being too cold [7]. Other research has suggested that UK death rates rise between $0.9 \%$ and $2.8 \%$ for every degree Celsius drop in the outdoor temperature [8]. The prevalence of cold

\footnotetext{
* Corresponding author

Email address: A.L.Hardy@leedsbeckett.ac.uk (A. Hardy)
}

homes in the UK means that, cumulatively, they cost the National Health Service (NHS) an estimated £1.36 billion each year [9]. Under-heating of UK homes therefore has major implications for both citizens and the government.

There is no single reason that UK homes are underheated, but a contributory factor is often low income. Households on a low-income have been reported as rationing fuel use to avoid high fuel bills and getting into debt [10. Additionally, the UK building stock includes many properties with low energy efficiency, as over $80 \%$ of UK homes were built prior to the first building energy efficiency regulations 11]. Heating these older properties can therefore prove expensive even for those on higher incomes. Finally, high fuel prices can deter consumers from using a sufficient amount of energy to heat their homes. Fuel prices have increased faster than inflation in recent years [12], and many customers find themselves on expensive fuel tariffs which can further deter any expenditure on heat.

\subsection{Housing Energy Policy}

The UK government has introduced several measures to combat the trilemma of low household incomes, excess dwelling heat loss, and high fuel prices. For households on low-incomes, the Warm Home Discount Scheme, Cold Weather Payments and Winter Fuel Payments have been established to help pay for the energy required to heat their homes. To tackle the inefficiency of the UK housing stock, there has been substantial investment in improving 
the efficiency of homes. New-build houses now have to adhere to increasingly strict regulations designed to ensure high energy efficiency [13]. Existing houses can also receive financial support to improve their homes via schemes such as the energy company obligation (ECO) [14]. Finally, to address the issue of high fuel prices, the regulator for the electricity and gas markets in GB (ofgem) have historically provided guidance to customers on how to engage with the energy market and obtain a cheap price for energy. However, despite the existence of such guidance, engagement with the energy market has remained low. For example, consumers have reported a mistrust of energy companies and a fear of "getting a worse deal" [15], while other customers are unaware that switching tariffs is even possible 16].

\subsection{Equity, overpayment and switching}

Due to the small number of customers engaging in the energy market, it is estimated that many households are overpaying on their energy bills; in 2016, it was found that UK customers overpaid a total of $£ 1.4$ billion when compared to the cheapest available deals [16]. Many of these customers are overpaying as consequence of how the UK energy market operates; UK customers sign up to a fixed rate contract and, upon expiry, are automatically moved onto the more expensive standard variable-rate tariff (SVT). Market-conscious customers may search for a new contract or switch supplier, but switching rates are low and up to $66 \%$ of customers lapse onto the expensive SVT [17.

Households from certain demographic groups are less likely to switch from their expensive SVTs than others. The competition market authority (CMA) report that people with low incomes, who are living in rented accommodation or who are above 65 are more likely to be on SVTs [16. The fact that those with a low-income are more likely to be on an expensive SVT is a troubling association, as it is these low-income households that could benefit the most from cheaper energy deals. Switching rates are also lower among those who use prepayment meters [16. Prepayment meters operate on a "pay as you go" basis, with customers paying for energy before they use it. The CMA reports that the low level of switching amongst prepayment customers is partly due to the higher rate of the previously mentioned characteristics (low-income, living in rented accommodation etc.) found in prepayment meter customers. In addition, those on prepayment meters would require a new energy meter if they want to take advantage of cheaper direct-debit tariffs, adding an extra barrier to switching. Prepayment customers also tend to be offered worse deals that those who pay by other methods with the result that any prepayment customers who do switch from their SVT tend to save much less.

\subsection{The Price Cap}

To tackle the issue of prepayment customers overpaying for their energy, ofgem imposed a price cap on prepayment
SVTs in April 2017. The price cap does not cap total energy bills, but instead defines the maximum amount that can legally be charged per unit of energy. The prices are set based on a CMA benchmark, which calculated the typical detriment (or overspend) of prepayment customers when compared to a competitive deal [16]. These numbers are then adjusted every 6 months to account for changes in the wholesale price of energy, inflation and environmental levy forecasts.

The price cap was initially applied to the 4 million prepayment meter customers in GB but, as of February 2018, the cap has also been applied to the 1 million customers who receive the warm-homes discount. The cap is designed to give these customers a better deal for their energy, allow customers to heat their homes to a more comfortable level and lessen levels of fuel poverty. However, when calculating the potential savings caused by the price cap, a typical domestic consumption for a household in GB was assumed. The effect of the price cap on those who do not conform to this assumption has not been studied. This paper uses smart meter data to calculate what the fuel bills of customers would be under price cap conditions, and test if the assumptions are valid. Of particular interest is the way the legislation treats those on prepayment economy 7 (EC7) tariffs. EC7 tariffs are different from standard rate tariffs, in that they receive cheaper electricity for 7 off-peak hours, but have to pay a premium for peak electricity use. EC7 (and the similar economy 10) tariffs where originally designed for customers who use a product such as storage heating, and therefore can ensure high off-peak electricity use. However, the premium charged for peak electricity on an EC7 tariff means that they can be considerably more expensive if used incorrectly. The price-cap legislation assumes that prepayment EC7 customers use $42 \%$ of their electricity during the off-peak period. However, the legislation does not make any concessions around the sensitivity of the policy outcome if this assumption is violated. In this work, we use energy-use profiles of real homes to determine what typical fuel use and fuel bills would be for different demographics, including the EC7 customers, to evaluate the success of the policy regarding its equity and efficiency.

\section{Data Analysis}

\subsection{Gas and Electricity Use}

Determining the effect of the energy price cap requires a knowledge of how different demographics tend to use their heating systems. The Energy Demand Research Project (EDRP) gathered data which traced utility usage for 18,370 households in the England and Scotland[18. Energy use was recorded using smart meters every thirty minutes for an average monitoring duration of 631 days. Additional data were also collected describing household's geographic location (Local Distribution Zone and Grid supply point) 
and electricity tariff type (standard or EC7). Each household was also placed in a demographic group, described by the Acorn system [19] (see Table 1).

Four energy companies were involved in the recruitment of participants for the EDRP: EDF, Eon, Scottish Power and SSE. The sampling strategy varied between companies, but in all cases a degree of stratification was involved. EDF stratified by estimated annual consumption, meter type and demographic information. Eon stratified their sample according to a four-fold categorisation of "fuel poor", "not fuel poor", "high use dual fuel customers" (defined as those consuming more than $7,000 \mathrm{kWh}$ of electricity per year) and EC7 customers. Scottish power stratified by the energy use of its customers. SSE straitified their sample by fuel mix (electricity only or dual fuel) and demographic. EDF is the only company which recruited EC7 customers, and the EDF sampling strategy required that EC7 customers in their sample also use an EC7 heating product such as storage heaters. The publicly available EDRP data were downloaded from the UK data archive [20]. Several households were missing from the available data, resulting in data from 14,621 being downloaded. Additionally, houses with missing demographic or geographic information were removed, along with houses whose monitoring duration was less than 365 days, as at least a full year's worth of data is required to capture the total annual fuel bill and allow comparison with other properties.

In houses which fulfilled the above criteria, there remained instances where data were missing. In these cases, the following procedure was followed to fill-in these missing data. First, all time-series were cut to one year's worth of data and missing time steps were padded with NA values to ensure all time series were of the same length. If entire days' worth of data were missing, an attempt was made to fill these missing days with data of an equivalent date from a different year. If this was not possible, a median profile of winter and summer use was generated for each household, and this median profile was used to fill in the missing day. An analysis of any remaining missing data was then conducted. It was then noted that some smart meters were consistently missing data from particular hours of the day. If these missing data fell within a peak-use period, the time-series would be biased to lower total energy uses. A check for these consistent dropouts was therefore conducted, and any time series which was missing more than $5 \%$ of the data from a particular hour was removed.

After these steps had been conducted, some time series maintained a small number of randomly distributed missing values. These values were tolerated, providing the amount of missing data did not exceed $5 \%$ of all data. The resulting database contained data for 11,878 households. The median annual electricity use for each Acorn group was then calculated and is displayed in figure 1, with uncertainties calculated using a bootstrap procedure. The electricity use is split depending on if the customers use a standard or an EC7 meter. Most Acorn groups show significantly higher electricity use among the EC7 customers, as would be expected when EC7 heating products are used. In those groups which do not show a significant difference, the reason may be due to a smaller sample size. For example, Acorn group P only contained 13 EC7 customers which contributes to its wide error bar. Ofgem publishes "Typical Domestic Consumption Values" (TD$\mathrm{CVs}$ ) that describe annual electricity and gas use for typical customers 21. At the time the smart meter data were taken, the TDCV of a median-use customer was $3300 \mathrm{kWh}$ for standard rate customers, and $5000 \mathrm{kWh}$ for EC7 customers. The average electricity use of the EC7 customers is somewhat lower than the TDCV for most demographics, suggesting that many EC7 households in this sample use less electricity than is typical.

The average annual gas use for homes with a gas meter installed is displayed in figure 2. Again, the gas use is split depending on if the customers use a standard or an EC7 meter for their electricity. It might be expected that customers with an EC7 product would use significantly less gas than those without. However, this is not the case, and some EC7 customers are still using considerable gas. In these homes it is likely that, although an EC7 heating product is installed, it is being supplemented by considerable gas heating. Again, many of the customers in this sample appear to use less gas than suggested by ofgems' TDCV, as an annual use of $16,500 \mathrm{kWh}$ was considered as median gas use [21].

\subsection{Fuel Bills}

Energy tariffs typically consist of a fixed amount charged per day (the standing charge), and cost associated with one unit of energy (the unit rate). The standing charges and unit rates of prepayment SVTs were obtained directly from the "Big 6" energy suppliers (British Gas, EDF, Eon, NPower, Scottish Power and SSE). These prices were all consistent with the April 2018 price cap conditions. The Big 6 energy companies supplied energy to $\sim 80 \%$ of UK customers in the third quarter of 2017 [22] and these tariffs are therefore broadly representative of what prepayment meter customers are likely to pay. It was noted that the standard tariffs offered by the big 6 companies tend to group around the maximum values allowed within the cap (see table 2), and little variation therefore exists within these prices.

Like the standard tariffs, the standing charges for the capped EC7 tariffs also group around the maximum allowed value. However, the unit rate in EC7 tariffs show more variation than the standard rate tariffs due to the way in which EC7 tariffs are handled within the legislation. Rather than define a maximum amount that can be charged during both the peak and off-peak periods, energy suppliers are permitted to choose any rate provided the total price for $4,600 \mathrm{kWh}$ of electricity does not exceed a fixed amount, assuming a split of $42 \%$ off-peak use, and $58 \%$ peak use. A energy company can therefore charge more for electricity used during peak periods, providing 


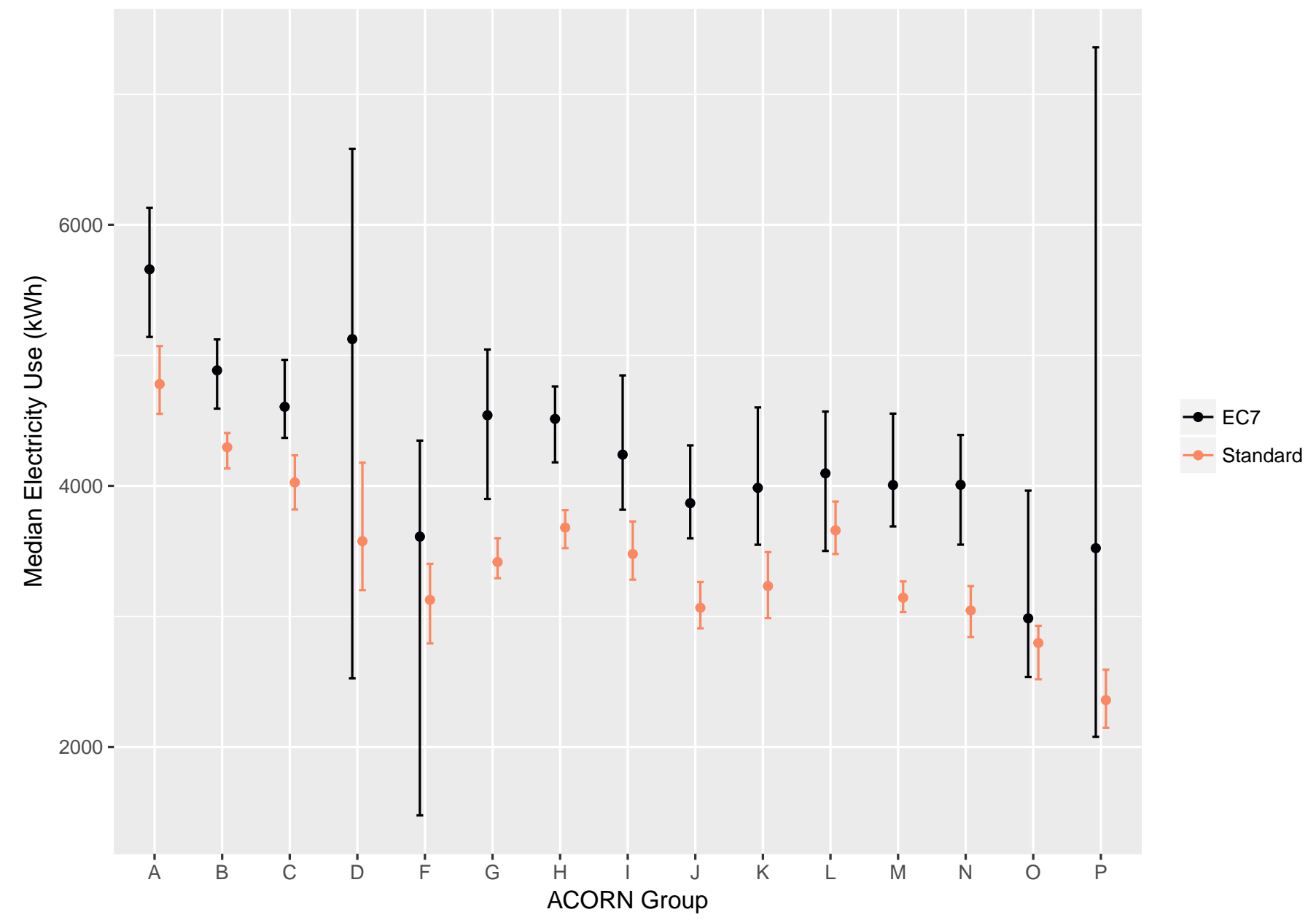

Figure 1: Median electricity use for each Acorn group. The majority of groups show greater electricity use for their economy 7 customers, as would be expected if a economy 7 heating product is used. 


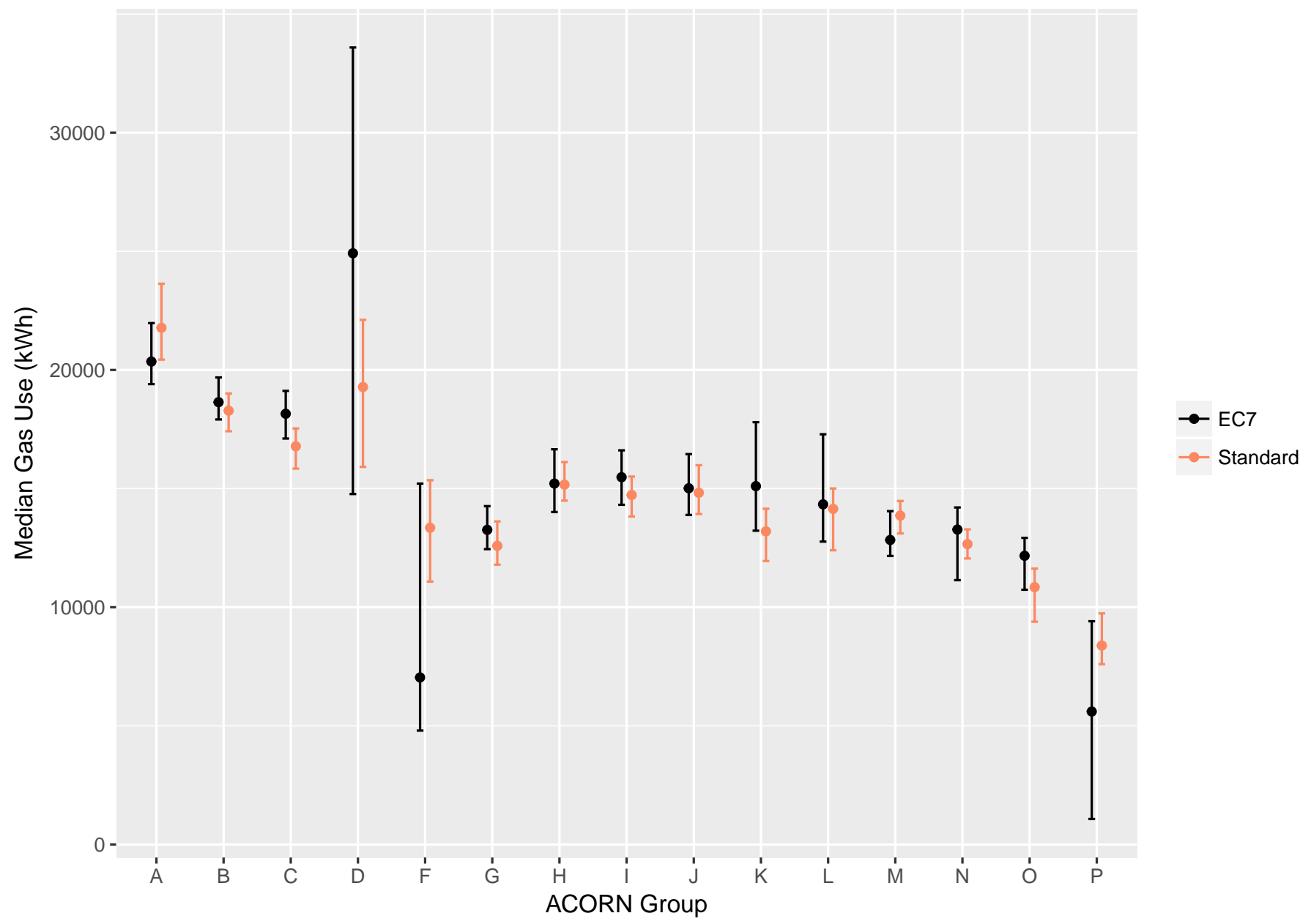

Figure 2: Median gas use for dwellings with a gas supply. Despite using economy 7 products, the economy 7 customers often do not show significantly lower gas use than standard tariffs. economy 7 customers may therefore still be relying on gas heating systems. 
Table 1: Acorn Groups

\begin{tabular}{cccc}
\hline \hline Group & Description & Average Income $(£)$ & Sample Size \\
\hline A & Lavish Lifestyles & 74021.4 & 1250 \\
B & Executive Wealth & 61981.7 & 2089 \\
C & Mature Money & 44118.1 & 1008 \\
D & City Sophisticates & 54954.4 & 194 \\
F & Countryside Communities & 38338.2 & 172 \\
G & Successful Suburbs & 44307.9 & 673 \\
H & Steady Neighbourhoods & 39820.0 & 1129 \\
I & Comfortable Seniors & 27946.0 & 663 \\
J & Starting Out & 39731.5 & 713 \\
K & Student Life & 28854.6 & 551 \\
L & Modest Means & 30070.5 & 639 \\
M & Striving Families & 27416.2 & 1261 \\
N & Poorer Pensioners & 16932.4 & 776 \\
O & Young Hardship & 26112.8 & 352 \\
P & Struggling Estates & 23673.1 & 269 \\
\hline
\end{tabular}

Table 2: Tariff information for Single Rate Electricity under the April 2018 price cap for the East Midlands

\begin{tabular}{ccc}
\hline \hline Company & Standing Charge & Unit rate \\
\hline Maximum allowed & $\mathbf{3 0 . 4 2}$ & $\mathbf{1 4 . 0 9}$ \\
British Gas & 30.41 & 14.08 \\
EDF & 30.41 & 14.09 \\
Eon & 30.41 & 14.08 \\
NPower & 30.41 & 14.08 \\
Scottish Power & 30.41 & 14.09 \\
SSE & 30.41 & 14.08 \\
\hline
\end{tabular}

they offset this with a lower charge for the off-peak period. This variation is demonstrated in Figure 3, which shows the EC7 prepayment SVTs for a house in the East of England.

The price-cap tariffs offered by the big-6 energy companies were used to calculate a typical annual fuel bill for each household in the sample (see Fig. 4). Some of the houses in the sample had no gas data, but it was not known if this was due to the house being electricity-only, or due to a lack of a gas smart meter. For the purpose of price calculation, only properties with both electricity and gas smart meters were therefore included. Uncertainties were calculated using a bootstrap method. For EC7 tariffs, the lower-rate period was assumed to be $12 \mathrm{pm}$ to $7 \mathrm{am}$. The start and end times for the EC7 tariffs are at the discretion of the energy company and information on this exact period is not freely available for all tariffs. However, the low-rate period is unlikely to vary considerably from the assumed period.

The price-cap legislation was designed to bring prepayment fuel bills down so that they are more competitive with a reference "benchmark" deal. For a median-use household, this benchmark bill was $£ 775$ per year 16 . For many of the lower-income acorn groups (M-P) on standard rate electricity, the average fuel bill does indeed appear to be within this range. This is not the case for EC7 customers as in many demographics, the EC7 customers show higher fuel bills than those on standard tariffs. This is likely, in part, due to their apparently high gas use despite the owning of EC7 heating products. In addition, the amount of electricity used during the off-peak hours (between 12 and $7 \mathrm{am}$ ) was noted to be low. Cost-effective use of EC7 tariffs relies on shifting as much electricity use as possible to the off-peak period. As displayed in Fig. 5. many EC7 customers in this sample use around $75 \%$ of their electricity during the day. This amount of daytime use is similar to those on standard rate tariffs, and suggests many customers on EC7 tariffs would be better off switching to a standard tariff.

The fuel price legislation assumes electricity use is split at $42 \%$ night use, and $58 \%$ day use. As most EC7 customers use more electricity during the day, the majority will also spend more on $4,600 \mathrm{kWh}$ of electricity than is allowed by the price cap. To determine how much more, the cost of 4,600 kWh of electricity was calculated for each EC7 customer and for each of the big 6 energy company's tariffs. The results are displayed in Figure 6, with the red horizontal line denoting the maximum amount customers should be charged under the price cap legislation. The different rates charged by the energy companies for peak and off-peak use has a noticeable effect on how much EC7 customers spend. Customers who are able to reduce their daytime electricity use to below $58 \%$ will find themselves rewarded most with an Npower tariff. However, if their electricity use strays above the $58 \%$ split, the same Npower tariff will penalise customers to a greater degree than other tariffs.

\subsection{Fuel Poverty}

The increased fuel bills experienced by EC7 customers may also increase their chances of being in fuel poverty 


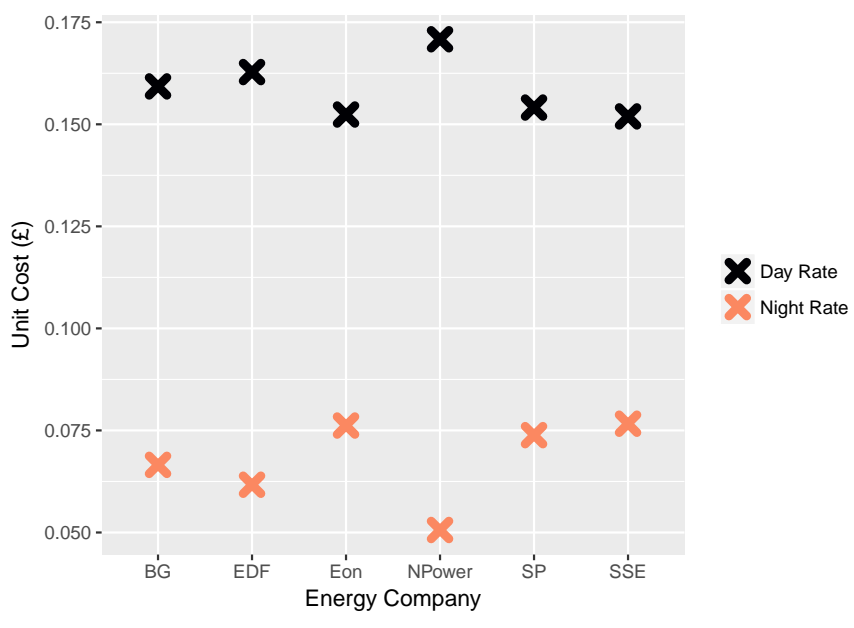

Figure 3: Comparison of the electricity unit costs of economy 7 tariffs for the "big 6" energy companies. The price-cap only limits the amount that can be charged for $4,600 \mathrm{kWh}$ of electricity, assuming a $42 \%$ off-peak use, and $58 \%$ peak use. Companies can therefore charge higher rates for peak electricity use if they offset this with low charges for off-peak use.

(FP). Assessing whether or not a household would be in FP requires knowledge of the household income. This information was not made available in the EDRP dataset, and an accurate assessment of FP is therefore not possible. However, average income information is associated with each Acorn demographic, and this income allows an approximate risk of FP to be assessed (see Table 1). The UK government adopts a Low-Income High-Cost (LIHC) definition of FP. In the LIHC definition, a household is classified as fuel poor if it's required energy cost is high (greater than the median), and if its disposable income, after spending on fuel, would put it below the poverty line 23. To determine if the households in this work might be in FP, any houses whose fuel cost exceeded the UK median were first extracted [24. Houses which fulfilled this criteria were then assigned an approximate income based on their demographic and their disposable income, after spending on fuel, was calculated. The poverty line is defined as $60 \%$ of the national median disposable income [25] and any households who additionally fulfilled this criteria were classed as being at risk of FP.

In the sample as a whole, there was no significant difference between FP probability for EC7 and standard tariffs. Many demographics show no risk of $\mathrm{FP}$ at all due largely to their high income. However, assuming average acorn salaries, FP was found to occur in Acorn groups I, K, M, N and P. Furthermore, a significant difference in FP probability was found between standard rate and EC7 customers in group $\mathrm{N}$ : poorer pensioners. In group $\mathrm{N}$, the percentage of EC7 customers $(n=107)$ in FP was found to be $50_{-10}^{+9} \%$, whilst the percentage of standard rate customers $(\mathrm{n}=364)$ in FP was found to be $34 \pm 5 \%$. Pensioners are typically associated with greater levels of occupancy during the day than other demographics, which would be associated with additional heating demand during this period. The increased incidence of FP risk for EC7 customers may therefore be due to their relatively high electricity use during peak hours compared to other demographics.

\section{Discussion}

The analysis in the previous section assumes that the consumption of each household was such that a comfortable and safe level of warmth was achieved. However, it is likely that many of the households in this study adjusted their utility consumption based on their income and the actual tariff they were on. Low-income households may then use less energy than required to maintain a comfortable and safe internal temperature. Indeed, a general negative trend seems to exist between acorn income and the fuel use displayed in Figures 11 and 2, Furthermore, Acorn group $\mathrm{P}$ displayed median gas use well below the TDCV, suggesting that under-heating may be occurring frequently within this group. Any reduced consumption would have the result that a lower than typical fuel bill would have been calculated, and these houses could therefore be overlooked in the definition of FP. The FP risk presented in Section 2.2 should therefore be considered only a lower estimate. To avoid issues of under-heating affecting government statistics, the UK government rely on modelled utility use assuming a safe internal temperature is always obtained. However, these modelled consumption values are also associated with many uncertainties and limitations, as they generalise building types and heating schedules. Whilst the smart meter data used in this study cannot accurately determine levels of FP, it can capture real heating patterns and unusual features which are not captured by standardised heating profiles.

Another potential limitation of using the EDRP smart meter data as a metric for typical energy consumption is that the smart meters installed in the EDRP were an intervention which may have reduced typical consumption [18. The smart meter data may therefore be biased to lower values than is typical in a household. The EDRP reports that utility use was indeed reduced by approximately $3 \%$ in their smart meter trials. However, the EDRP data ceased being recorded in 2010 and between 2010 and 2016, temperature corrected domestic energy consumption in the UK also fell by $\sim 5 \%[26$. This was partially due to the increased use of energy efficiency measures such as loft insulation. Current consumption of UK homes is therefore likely to be slightly below that reported in the EDRP, but this difference is not likely to be much more than $2 \%$.

\section{Conclusion and Policy Implications}

Energy price caps have historically proven themselves to be difficult to implement 27] and often draw criticism for their effect of stifling competition and reducing innovation [28]. It is certainly the case that for the GB prepayment meter price cap, prices have tended to bunch around 


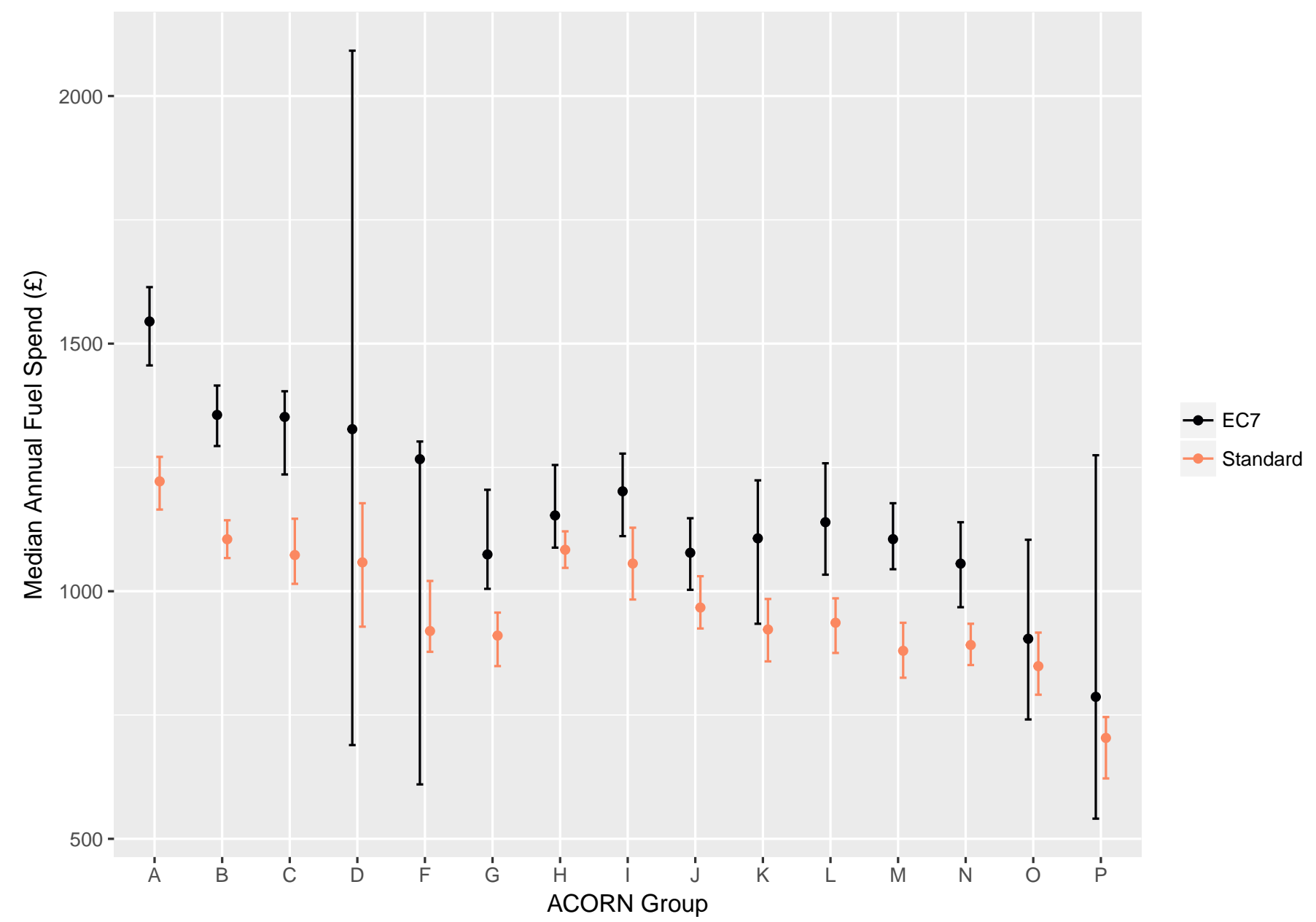

Figure 4: Median annual fuel spend if all dwelling were subject to the April 2018 price cap. economy 7 customers often pay noticeably more than standard customers. 


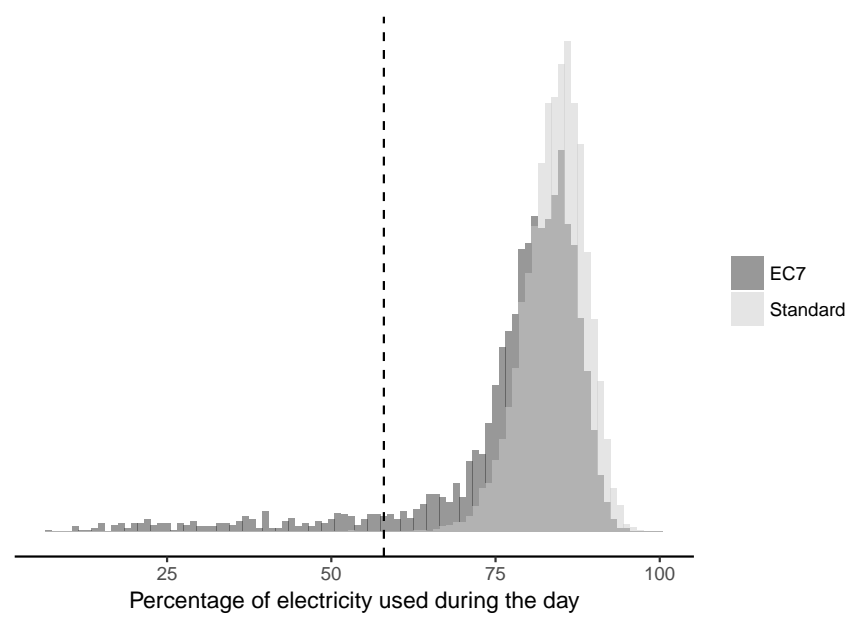

Figure 5: Proportion of electricity used during the peak (daytime) hours for both economy 7 (EC7) and standard customers. The dashed line shows where the peak in economy 7 use should be according to the economy 7 fuel cap legislation. Very few economy 7 customers use electricity in the percentage assumed in the price cap, and the majority of economy 7 customers use electricity in similar proportions to standard rate customers.

the cap which suggests a lack of competition (see Table 2). However, proponents of price caps will highlight these customers were unlikely to engage with the market in the first place [16], and the lack of competition may not have a considerable detriment on these customers. Furthermore, even a capped non-competitive prepayment market was expected to cause savings of hundreds of pounds for many customers who were previously on uncapped tariffs [29]. This study suggests that the energy price cap will have been successful in reducing energy bills to the level expected for many customers in low income demographics. If all customers in the study were subject to the energy price cap, the annual fuel bills of many customers would be equal to or below the benchmark deal used as a basis for the legislation. However, customers on EC7 tariffs have significantly higher annual fuel bills in most demographics and would therefore not recieve as much benefit from the price cap. The result that EC7 customers tend to spend more under price cap conditions is concerning, as EC7 heating systems have been associated with increased levels of FP - $48 \%$ of households in Scotland with storage heaters were found to be fuel poor, compared to $31 \%$ of households that use mains gas 30]. Price caps also raise a potential issue for vulnerable customers who do engage in the energy market. Imposing a cap on certain tariffs may cause energy suppliers to raise prices on other tariffs to compensate 31. Any vulnerable customers who do engage with the energy market may then find the cheap deals that were previously available to them have been removed. The potential ethical issues surrounding price caps are outside the scope of this work, but are a factor which could be considered when designing future legislation.

Under normal market conditions, it is common for a house which utilises storage heaters and EC7 to spend more than a house which uses gas. Indeed, ofgem have shown that a 3 -bedroom house would have cost $£ 1478$ in 2015 to heat with storage heaters on an EC7 tariff and $£ 1064$ for a gas fired boiler 30. However, the EC7 price caps were designed with this discrepancy in mind, and aimed to address this difference with more favourable EC7 prices. The failure to fully address this issue in our sample is, in part, because the price cap does not account for the the high use of peak electricity displayed by most EC7 customers. Addressing the issue could therefore be achieved by assuming higher peak energy use in the price cap legislation. The EC7 customers themselves could also shelve some of the blame for the higher prices as they are not using their heating system in a cost-effective manner. This may be due to confusing heating controls, a misunderstanding of the costs involved or a genearl lack of engagement. Another way to handle the misuse of EC7 heating systems would therefore be to address the houses with EC7 heating systems directly. This could be in the form of guidance to customers to ensure they know how to use their system correctly, and maintenance to ensure the heating system is operating as expected. A more extreme solution could be to remove the storage heaters entirely and install either gas heating or a low-carbon alternative such as heat pumps. Heat pumps would be particularly useful for properties that have no gas supply, and would also be in line with the UKs drive to decarbonise heat. Storage heating systems are found disproportionately in private-rented and social housing compared to other sectors [30, and schemes to remove EC7 systems could therefore target landlords, housing associations and local authorities.

The potential failure of the price cap for EC7 customers stems from assumptions around how households use energy not being met. EC7 tariffs are becoming less common, and a gradual reduction in EC7 customers might be expected over time. However, there are an increasing number of time-of-use (ToU) tariffs being offered. Like EC7 tariffs, ToU tariffs utilise multiple electricity rates depending on the time of day, with peak electricity being the most expensive. A report commissioned by ofgem suggests that the majority of customers would change their electricity consumption in response to a ToU tariff and therefore receive lower fuel bills 32. However, if the assumptions on electricity consumption patterns in this report also prove to be incorrect, then ToU customers could also find themselves with high fuel bills. Given the lack of engagement in the UK energy market [16, ToU tariff customers in this situation may not realise they are overspending and may not switch back to a standard rate tariff. ToU tariffs should therefore be introduced with caution, especially within vulnerable demographics, and all assumptions on expected consumption behvaiors should undergo rigorous testing. A potential solution to lapsing and unsuitable ToU tariffs could be to force ToU tariffs which expire onto a standard rate SVT rather than a ToU SVT. If implemented on EC7 tariffs, a policy such as this could have 


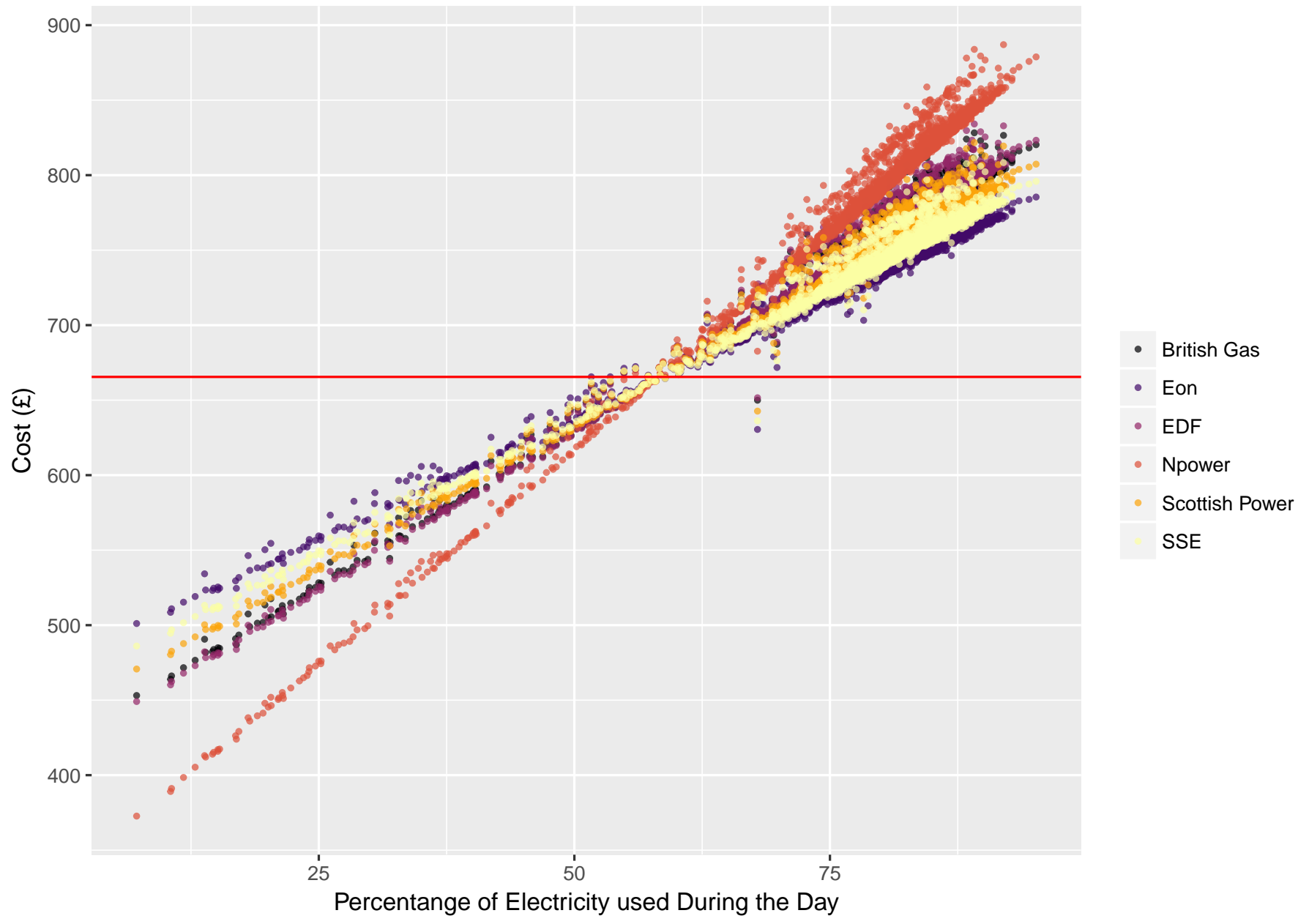

Figure 6: Amount that each economy 7 tariff house would spend on $4600 \mathrm{kWh}$ of electricity with the "big 6" energy companies in the GB under the October 2017 price cap. The horizontal red line denotes the maximum price as stipulated in the price cap, and was calculated assuming economy 7 customers use $58 \%$ of their electricity during the peak period. The majority of houses clearly use more electricity during the peak period than assumed by the price-cap and would therefore pay more than the maximum allowed. 
benefited many of the EC7 customers in this study, as they behave like standard rate electricity users likely without realising.

Prepayment meter customers (and subsequently, warm home discount customers) were initially targeted with the energy price cap because these groups were identified as being at risk of FP 16]. At the time of writing, plans to extend this energy price cap to all SVTs were under way to further protect customers. Despite the initial targeting, these blanket price caps remain a blunt tool that affects different customers to different degrees. Bespoke targeting of vulnerable customers would likely be more equitable, but such bespoke identification has previously been a challenge. As suggested in this study, smart meter data may allow more specific identification of vulnerability to be achieved and therefore may allow for more targeted policy. For example, customers in Acorn Group N (Poorer pensioners) and with EC7 heating were identified as having the highest FP risk in this work. With additional information such as accurate income data, even more specific identification of vulnerability could likely be achieved. In this case, the need for blanket price caps could be removed altogether.

\section{References}

[1] R. Critchley, J. Gilbertson, M. Grimsley, G. Green, W. F. S. Group, et al., Living in cold homes after heating improvements: evidence from warm-front, englands home energy efficiency scheme, Applied Energy 84 (2) (2007) 147-158.

[2] C. Liddell, C. Morris, Fuel poverty and human health: a review of recent evidence, Energy policy 38 (6) (2010) 2987-2997.

[3] J. Evans, S. Hyndman, S. Stewart-Brown, D. Smith, S. Petersen, An epidemiological study of the relative importance of damp housing in relation to adult health, Journal of Epidemiology \& Community Health 54 (9) (2000) 677-686.

[4] Public Health England, Cold weather plan for england (2015).

[5] BRE, Energy follow up survey, report 2: Mean household temperatures (2013).

[6] T. Oreszczyn, S. H. Hong, I. Ridley, P. Wilkinson, Determinants of winter indoor temperatures in low income households in england, Energy and Buildings 38 (3) (2006) 245-252. doi:http://dx.doi.org/10.1016/j.enbuild.2005.06.006 URL http://www.sciencedirect.com/science/article/pii/ S0378778805000964

[7] Office for National Statistics, Excess winter mortality in england and wales: 2016 to 2017 (provisional) and 2015 to 2016 (2017).

[8] P. Wilkinson, M. Landon, B. Armstrong, S. Stevenson, M. McKee, Cold comfort: the social and environmental determinants of excess winter death in England, 1986-1996, Joseph Rowntree Foundation, 2001.

[9] BRE, The cost of poor housing to the nhs (2015).

[10] W. Anderson, V. White, A. Finney, "You just have to get by" Coping with low incomes and cold homes, EagaCT, 2010.

[11] DCLG, English housing survey, headline report (2016).

[12] JRF, Uk poverty 2017: A comprehensive analysis of poverty trends and figures (2017).

[13] HM Government, The building reguations 2010 (2010).

[14] Energy Company Obligation Order, The electricity and gas (energy company obligation) (amendment) order 2017 (2017).

[15] A. M. Tod, A. Lusambili, C. Homer, J. Abbott, J. M. Cooke, A. J. Stocks, K. A. McDaid, Understanding factors influencing vulnerable older people keeping warm and well in winter: a qualitative study using social marketing techniques, BMJ open 2 (4) (2012) 922.
[16] CMA, Energy market investigation: Final report (2016).

[17] Ofgem, Retail energy markets in 2016 (2016).

[18] AECOM Building Engineering, Energy demand research project: Early smart meter trials, 2007-2010, UK Data Service (2014). doi:10.5255/UKDA-SN-7591-1

[19] Acorn, The acorn user guide (2014). URL https://acorn.caci.co.uk/downloads/ Acorn-User-guide.pdf

[20] CSE, Edrp (2010).

URL https://discover.ukdataservice.ac.uk/catalogue/ ?sn=7591

[21] Ofgem, Review of typical domestic consumption values (2013). URL https://www. of gem.gov.uk/ofgem-publications/74735/ tdcv-review-consultation-pdf

[22] Ofgem, Electricity supply market shares by company: Domestic (gb) (2018).

URL

https://www.ofgem.gov.uk/data-portal/ electricity-supply-market-shares-company-domestic-gb

[23] BEIS, Annual fuel poverty statistics report: 2017 (2017).

[24] BEIS, Annual domestic energy bills (2018). URL https://www.gov.uk/government/ statistical-data-sets/annual-domestic-energy-price-statistics

[25] Office for National Statistics, Persistent poverty in the uk and eu: 2015 (2017).

[26] BEIS, Energy consumption in the uk (2017).

[27] F. A. Wolak, Diagnosing the california electricity crisis, The Electricity Journal 16 (7) (2003) 11-37.

[28] F. A. Roques, N. S. Savva, et al., Price cap regulation and investment incentives under demand uncertainty, Electricity Policy Research Group, Judge Institute of Management, University of Cambridge, 2006.

[29] E. Business, I. S. Committee, Oral evidence: Energy price caps, hc 470 (2017).

URL http://data.parliament.uk/writtenevidence/ committeeevidence.svc/evidencedocument/ business-energy-and-industrial-strategy-committee/ energy-price-caps/oral/71540.pdf

[30] Ofgem, Insights paper on households with electric and other non-gas heating (2015).

[31] C. W. Price, Back to the future? regulating residential energy markets, International Journal of the Economics of Business 25 (1) (2018) 147-155. arXiv:https://doi.org/10. 1080/13571516.2017.1402469 doi:10.1080/13571516.2017. 1402469

URL https://doi .org/10.1080/13571516.2017.1402469

[32] Ofgem, Distributional impacts of time of use tariffs (2017). 